\title{
Antibodies against Carbonic Anhydrase in Patients with Aplastic Anemia
}

\author{
Jan Lakota ${ }^{a, b}$ Annika Lanz ${ }^{c}$ Maria Dubrovcakova ${ }^{b}$ Barbora Jankovicova ${ }^{d}$ \\ Asensio Gonzalez ${ }^{c}$ Martin Stern ${ }^{c}$ \\ ${ }^{a}$ Bone Marrow Transplantation Unit, National Cancer Institute, and b Laboratory of Molecular Oncology, \\ Cancer Research Institute, Slovak Academy of Sciences, Bratislava, Slovakia; ' Immunotherapy Laboratory, \\ Department of Biomedicine, University Hospital Basel, Basel, Switzerland; ${ }^{d}$ Department of Biological and \\ Biochemical Sciences, Faculty of Chemical Technology, University of Pardubice, Pardubice, Czech Republic
}

\section{Key Words}

Anti-thymocyte globulin · Aplastic anemia • Bone marrow transplantation $\cdot$ Carbonic anhydrase

\begin{abstract}
Background/Aims: Antibodies against carbonic anhydrase (CA) have been detected in patients with an aplastic anemia (AA)-like syndrome after autologous stem cell transplantation. Methods: We analyzed sera of 53 bona fide AA patients before and after treatment with anti-thymocyte globulin (ATG) or bone marrow transplantation for the presence of anti-CA antibodies. Results: Anti-CA antibodies were detected in 20 patients (38\%) and were associated with older age at diagnosis of AA. Antibody-positive patients showed poor response to ATG treatment (complete response 14\%) and inferior long-term survival (36\% at 10 years), when compared to antibody-negative patients (complete response and 10 -year survival both $64 \%$ ). Two thirds of patients with antibodies at diagnosis of AA became antibody negative after treatment with ATG. Clearance of the antibody did not appear to be associated with hematological improvement. Conclusion: Antibodies against CA are detected frequently at diagnosis of $A A$, and their presence identifies a subset of patients with poor response to immunosuppressive treatment.

Copyright $\odot 2012$ S. Karger AG, Basel
\end{abstract}

\section{Introduction}

Aplastic anemia (AA) is a rare disease characterized by the diminished or absent hematopoietic precursors in the bone marrow due to injury to the pluripotent hematopoietic stem cell. AA is successfully treated by bone marrow transplantation (BMT) or by immunosuppressive therapy (IST), usually including anti-thymocyte globulin (ATG) and cyclosporine [1]. Response rates in the range of $60-80 \%$ after IST suggest that in the majority of cases AA is an autoimmune disease [2]. In contrast to many other autoimmune diseases, the target of autoimmunity has so far not been elucidated, although some candidate genes have been suggested [3]. Analysis of T lymphocytes in AA patients has identified a pathogenetic role for both CD8 and CD4 T cells $[4,5]$. Recent studies have also described antibodies against a variety of auto-antigens in AA patients, although their role in the pathogenesis of the disease remains unclear [6].

A clinical picture resembling AA may occur in patients with hematological or solid malignancies after

J.L. and A.L. contributed equally to this article.

\section{KARGER}

Fax +4161306 1234 E-Mail karger@karger.ch www.karger.com
Martin Stern, MD

Department of Biomedicine, University Hospital Basel

Hebelstrasse 20

$\mathrm{CH}-4031$ Basel (Switzerland)

Tel. +41 6132873 90, E-Mail sternm@ uhbs.ch 
high-dose chemotherapy and autologous stem cell transplantation. Recent work has demonstrated that antibodies against carbonic anhydrase (CA) may be found in a significant portion of these patients. Interestingly, development of anti-CA antibodies also correlated with regression of the underlying malignant disease, indicating that an autoimmune process may contribute to tumor control $[7,8]$.

Antibodies against CA have so far not been described in patients with AA. We aimed to elucidate the incidence and the prognostic significance of anti-CA antibodies in 53 AA patients treated at our institution with ATG or BMT for AA [9].

\section{Patients and Methods}

\section{Patients}

Serum samples of patients with AA were collected before and after treatment with ATG or BMT and stored at $-80^{\circ} \mathrm{C}$ until analysis. Patients underwent treatment with horse ATG plus cyclosporine or sibling donor $\mathrm{BMT}$ at a single institution as described previously [10]. Severity of AA and response to treatment were classified according to established guidelines $[11,12]$. Patients gave written informed consent to the analysis, and the study was approved by the local institutional review board.

\section{Detection of Anti-CA Antibodies}

The presence of antibodies against $40 \mathrm{ng}$ of commercial human CA I (purchased from Sigma-Aldrich Corporation, St. Louis, Mo., USA) was analyzed by Western blotting of patients' or healthy donors' sera which were diluted 500 times. Bands were quantified using the ImageJ software (http://rsb.info.nih.gov/ij). A patient previously characterized as strongly antibody positive [7] was used as internal reference in each batch of serum samples analyzed (defined arbitrarily as 1 unit). A population of healthy control donor sera was used to establish the lower reference range cutoff (mean +2 standard deviations)

\section{HLA Typing}

Patients from which cryopreserved bone marrow cells were available $(n=42)$ were typed for the presence of HLA-DR*15 using a commercial kit employing sequence-specific primers (OneLambda, Canoga Park, Calif., USA).

\section{Statistics}

Characteristics of patients with or without anti-CA antibodies were compared by Mann-Whitney U test for continuous or Pearson's $\chi^{2}$ test for categorical variables. The impact of antibody positivity on survival was analyzed by Kaplan-Meier analysis. Cumulative incidences of patients responding to treatment were calculated treating death in the absence of response as a competing risk. All $\mathrm{p}$ values are two-sided, and were considered significant if $<0.05$.
Table 1. Patient characteristics

$\begin{array}{ll}\begin{array}{l}\text { Antibody- } \\ (\mathrm{n}=33)\end{array} & \begin{array}{l}\text { Antibody+ } \\ (\mathrm{n}=20)\end{array}\end{array}$

\begin{tabular}{|c|c|c|c|}
\hline \multicolumn{4}{|l|}{ AA etiology } \\
\hline Idiopathic & $30(91)$ & $17(85)$ & \multirow[t]{5}{*}{0.39} \\
\hline Drug induced & $2(6)$ & 0 & \\
\hline Benzene induced & 0 & $2(10)$ & \\
\hline Post-hepatitis & 0 & $1(5)$ & \\
\hline Post-EBV & $1(3)$ & 0 & \\
\hline \multicolumn{4}{|l|}{ Disease severity } \\
\hline Non-severe AA & $3(9)$ & $2(10)$ & \multirow[t]{3}{*}{0.90} \\
\hline Severe AA & $17(52)$ & $9(45)$ & \\
\hline Very severe AA & $13(39)$ & $9(45)$ & \\
\hline HLA DR15 present & $12 / 28(43)$ & $6 / 14(43)$ & 1.00 \\
\hline \multicolumn{4}{|c|}{ Blood counts at diagnosis, $10^{9} / 1$} \\
\hline \multicolumn{4}{|c|}{ Neutrophils } \\
\hline Median & 0.238 & 0.199 & \multirow[t]{2}{*}{0.89} \\
\hline Range & $0-1.391$ & $0.016-1.468$ & \\
\hline \multicolumn{4}{|l|}{ Reticulocytes } \\
\hline Median & 13 & 6 & \multirow[t]{2}{*}{0.49} \\
\hline Range & $0-166$ & $0-75$ & \\
\hline \multicolumn{4}{|l|}{ Platelets } \\
\hline Median & 11 & 12 & \multirow[t]{2}{*}{0.76} \\
\hline Range & $2-95$ & $3-124$ & \\
\hline \multicolumn{4}{|l|}{ First-line treatment } \\
\hline ATG & $25(76)$ & $14(70)$ & \multirow[t]{2}{*}{0.65} \\
\hline BMT & $8(24)$ & $6(30)$ & \\
\hline \multicolumn{4}{|l|}{ Patient sex } \\
\hline Male & $14(42)$ & $9(45)$ & \multirow[t]{2}{*}{0.85} \\
\hline Female & $19(58)$ & $11(55)$ & \\
\hline \multicolumn{4}{|c|}{ Patient age at diagnosis } \\
\hline Median & 22 & 38 & \multirow[t]{2}{*}{0.04} \\
\hline Range & $2-63$ & $4-73$ & \\
\hline
\end{tabular}

Figures in parentheses indicate percentages.

\section{Results}

Fifty-three patients treated for AA between 1980 and 2002 at our institution with ATG $(\mathrm{n}=39)$ or BMT $(\mathrm{n}=14)$ were included in the analysis. Median follow-up of surviving patients in this cohort was 17 years (range 11-24). Pretreatment sera were available in all patients. In the majority of patients $(n=42)$, one or more posttreatment sera were also analyzed; they had been collected between 1 month and 12 years after initial therapy for AA. The median number of sera analyzed per patient was 5 (range 1-9).

\section{Antibodies against CA Are Frequent in}

Patients with AA

Before initiation of treatment, antibodies against CA were detectable in 20 patients ( $38 \%$ of the population). 


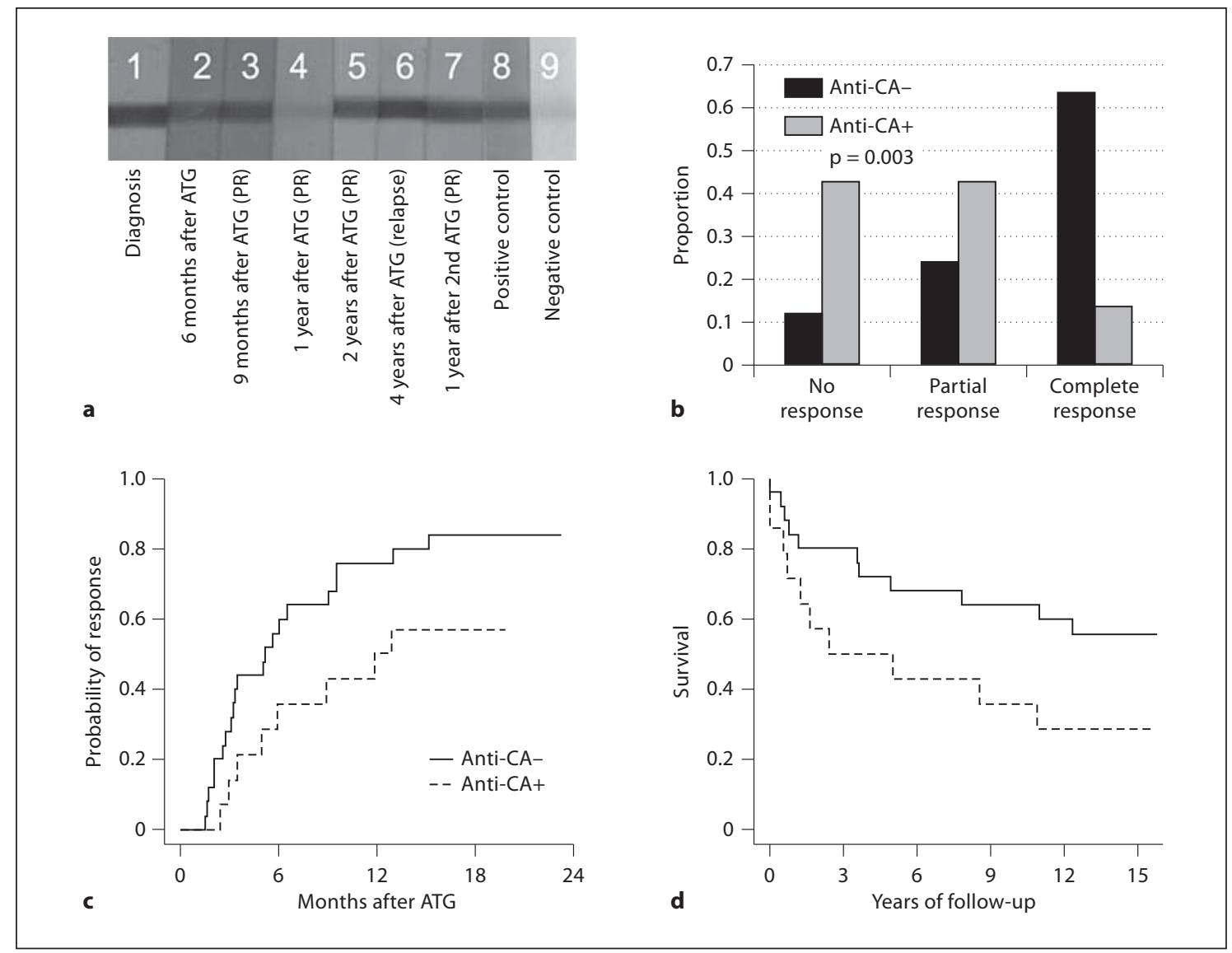

Fig. 1. a Antibodies against CA detected with Western blot in a patient with AA at diagnosis (lane 1), and at different time points after treatment with ATG. b Response rate to IST with ATG + cyclosporine in patients with or without anti-CA antibodies at diagnosis. c Cumulative incidence of response to IST in patients with or without anti-CA antibodies. d Overall survival in patients with or without anti-CA antibodies treated with IST.

Characteristics of patients with and without detectable anti-CA antibodies are summarized in table 1. Patient gender, etiology of AA, and disease severity were not significantly different between antibody-positive and antibody-negative patients. No difference was found in the frequency of patients carrying HLA-DR* 15 , a class II HLA antigen previously found to be overrepresented in AA [13]. Anti-CA-positive patients were older at diagnosis of AA (median 38 years vs. 22 years in anti-CA-negative patients).

In 10 of the patients carrying anti-CA antibodies before treatment (9 treated with ATG, 1 with BMT), followup samples were available. In the patient treated with BMT, antibodies were no longer detectable 6 months after transplantation. In the patients treated with ATG, no clear picture emerged: 3 patients cleared the antibody after ATG and attained hematological improvement (UPN 279, 350, 468). Notably, in the last patient, the anti- body reappeared followed by AA relapse (fig. 1a and online suppl. fig. 1; for all online suppl. material, see www. karger.com/doi/10.1159/000338826). Three other patients became antibody-negative without hematological improvement (UPN 311, 331, 524). The remaining 3 patients achieved hematological improvement despite continuous positivity for anti-CA antibodies (UPN 569, 625, 646). Evolution of antibody positivity and hematological parameters are summarized in online supplementary figure 1 .

\section{Survival and Response to Immunosuppressive}

Treatment Is Poor in Patients with Anti-CAA

Antibodies

Of 39 patients treated with IST, 18 (46\%) achieved a complete response, and $12(31 \%)$ a partial response, whereas 9 patients (23\%) showed no improvement for a total response rate (CR + PR) of 77\%. Analysis of antibody 
positivity before treatment and response to immunosuppressive treatment showed an unexpected negative correlation. While 16/25 (64\%) antibody-negative patients achieved complete response to immunosuppressive treatment, only $2 / 14(14 \%)$ patients with detectable antibody before treatment responded completely. In contrast, the frequencies of patients showing no improvement to IST were 3/25 (12\%) for anti-CA-negative patients, and $6 / 14(43 \%)$ for anti-CA-positive patients (overall $p$ value $=$ 0.003 ; fig. 1b). Partial or complete responses were also achieved faster in patients without antibody (median time to response 3.6 months) than in patients with anti-CA antibodies (median time to response 6 months; fig. 1c).

The detrimental effect of anti-CA antibodies in patients treated with ATG was also evident from survival analysis, which showed a trend towards inferior longterm survival of antibody-positive patients if treated with IST: 10-year survival after ATG treatment amounted to $64 \pm 10 \%$ in antibody-negative versus only $36 \pm 13 \%$ in antibody-positive patients ( $\mathrm{p}=0.06$; fig. $1 \mathrm{~d})$.

\section{Clonal Complications}

Twelve of 39 patients developed a clonal complication after treatment with ATG. Eight patients developed paroxysmal nocturnal hemoglobinuria after treatment with ATG, 4/25 (16\%) antibody-negative patients and 4/14 (29\%) antibody-positive patients $(\mathrm{p}=0.35)$. Five patients developed myelodysplastic syndrome: $2 / 25$ (8\%) antibody-negative and $3 / 14(21 \%)$ antibody-positive patients $(\mathrm{p}=0.23)$.

\section{Discussion}

This is the first analysis of the incidence of antibodies against CA in patients with AA. CA is a protein that that catalyzes the interconversion of carbon dioxide and water to bicarbonate and protons, and is almost ubiquitously expressed. Anti-CA antibodies have been described in patients with connective tissue diseases such as lupus erythematosus or Sjögren's syndrome [14, 15]. In lupus patients, IgG antibodies that suppress hematopoiesis have been described, although the target they recognize has not been elucidated so far [16].

While AA is generally considered a T cell-mediated autoimmune disease, several recent studies have shown that AA patients frequently carry autoantibodies. Feng et al. [17] found antibodies against diazepam-binding inhibitor-related protein 1 (DRS-1) in 27/71 (38\%) of patients with $\mathrm{PNH}+\mathrm{AA}$ and in $2 / 32(6 \%)$ patients with PNH- AA. Response to IST was $100 \%$ in patients with
anti-DRS-1 antibodies, but only 55\% in patients without anti-DRS-1 antibodies. The same group later demonstrated antibodies against moesin in 25/67 (37\%) patients with AA. In contrast to antibodies against DRS-1, antimoesin antibodies were not associated with improved response to immunosuppressive treatment [18]. Most recently, antibodies against heterogeneous nuclear ribonucleoprotein (hnRNP) K were described in 85/273 (31\%) AA patients. Response to IST was $87 \%$ in antibody-positive patients compared to only $46 \%$ in antibody-negative patients. Interestingly, in serial measurements before and after IST, antibody titers against hnRNP $\mathrm{K}$ remained strongly positive in patients irrespective of their response to treatment [19]. The presence of these autoantibodies in AA patients does not imply their involvement in the pathogenesis of the disease and may be an epiphenomenon of the autoimmune process. Interestingly, however, an AA patient with multiple autoantibodies (including anti-DRS-1 and anti-moesin) was recently reported to have undergone successful treatment with the antiCD20-antibody rituximab after failure of IST with ATG and cyclosporine [20].

The finding that anti-CA antibodies occur after autologous stem cell transplantation in patients showing a clinical picture resembling AA prompted us to study anti-CA antibodies in AA [7]. We show that anti-CA antibodies occur in untreated AA patients at a frequency of $38 \%$, which is comparable to the frequency of antibodies against DRS-1, moesin, or hnRNP K. In contrast to antibodies previously detected in AA patients, presence of anti-CA antibodies was not associated with a better response to IST. In contrast, patients carrying anti-CA antibodies showed poor response to IST. Whether antibodies against CA might serve as a predictive marker of patients with poor response to IST, which might benefit from alternative treatment strategies (i.e. stem cell transplantation), will have to be assessed in future studies.

In conclusion, we show that a significant proportion of AA patients carry antibodies against CA. Half of patients treated with IST become antibody negative after treatment. No correlation was found between posttreatment antibodies and response, and response to IST was poor in anti-CA antibody-positive patients.

\section{Acknowledgements}

This study was supported by grants from the Swiss National Science Foundation (grant PPOOP3_128461/1), from the 'Stiftung für Hämatologische Forschung,' and from the Foundation for Cell Transplantation (J.L., M.D., B.J.). 


\section{References}

1 Young NS, Scheinberg P, Calado RT: Aplastic anemia. Curr Opin Hematol 2008;15:162168.

$>2$ Scheinberg P, Nunez O, Weinstein B, Biancotto A, Wu CO, Young NS: Horse versus rabbit antithymocyte globulin in acquired aplastic anemia. N Engl J Med 2011;365:430438.

3 Nissen C, Stern M: Acquired immune mediated aplastic anemia: is it antineoplastic? Autoimmun Rev 2009;9:11-16.

$\checkmark 4$ Bacigalupo A, Podesta M, Mingari MC, Moretta L, Van Lint MT, Marmont A: Immune suppression of hematopoiesis in aplastic anemia: activity of t-gamma lymphocytes. J Immunol 1980;125:1449-1453.

5 Nakao S, Takami A, Takamatsu H, Zeng W, Sugimori N, Yamazaki H, Miura Y, Ueda M, Shiobara S, Yoshioka T, Kaneshige T, Yasukawa M, Matsuda T: Isolation of a T-cell clone showing HLA-DRB1*0405-restricted cytotoxicity for hematopoietic cells in a patient with aplastic anemia. Blood 1997;89: 3691-3699.

-6 Hirano N, Butler MO, Von Bergwelt-Baildon MS, Maecker B, Schultze JL, O'Connor KC, Schur PH, Kojima S, Guinan EC, Nadler LM: Autoantibodies frequently detected in patients with aplastic anemia. Blood 2003;102: 4567-4575.

>7 Lakota J, Skultety L, Dubrovcakova M, Altaner C: Presence of serum carbonic anhydrase autoantibodies in patients relapsed after autologous stem cell transplantation indicates an improved prognosis. Neoplasma 2008;55:488-492.
Skultety L, Jankovicova B, Svobodova Z, Mader P, Rezacova P, Dubrovcakova M, Lakota J, Bilkova Z: Identification of carbonic anhydrase I immunodominant epitopes recognized by specific autoantibodies which indicate an improved prognosis in patients with malignancy after autologous stem cell transplantation. J Proteome Res 2010;9: 5171-5179.

-9 Yoshida N, Yagasaki H, Takahashi Y, Yamamoto T, Liang J, Wang Y, Tanaka M, Hama A, Nishio N, Kobayashi R, Hotta N, Asami K Kikuta A, Fukushima T, Hirano N, Kojima S: Clinical impact of HLA-DR15, a minor population of paroxysmal nocturnal haemoglobinuria-type cells, and an aplastic anaemiaassociated autoantibody in children with acquired aplastic anaemia. Br J Haematol 2008; 142:427-435.

10 Speck B, Nissen C, Tichelli A, Gratwohl A Treatment of aplastic anemia. Oncologist 1996;1:367-370.

11 Camitta BM: What is the definition of cure for aplastic anemia? Acta Haematol 2000 103:16-18.

12 Camitta BM, Thomas ED, Nathan DG, Gale RP, Kopecky KJ, Rappeport JM, Santos G, Gordon-Smith EC, Storb R: A prospective study of androgens and bone marrow transplantation for treatment of severe aplastic anemia. Blood 1979;53:504-514.

13 Sugimori C, Yamazaki H, Feng X, Mochizuki K, Kondo Y, Takami A, Chuhjo T, Kimura A, Teramura M, Mizoguchi H, Omine M, Nakao S: Roles of DRB1 *1501 and DRB1 *1502 in the pathogenesis of aplastic anemia. Exp Hematol 2007;35:13-20.

14 Inagaki Y, Jinno-Yoshida Y, Hamasaki Y, Ueki H: A novel autoantibody reactive with carbonic anhydrase in sera from patients with systemic lupus erythematosus and Sjogren's syndrome. J Dermatol Sci 1991;2:147154.
15 Itoh Y, Reichlin M: Antibodies to carbonic anhydrase in systemic lupus erythematosus and other rheumatic diseases. Arthritis Rheum 1992;35:73-82.

16 Liu H, Ozaki K, Matsuzaki Y, Abe M, Kosaka M, Saito S: Suppression of haematopoiesis by IGG autoantibodies from patients with systemic lupus erythematosus (SLE). Clin Exp Immunol 1995;100:480-485.

17 Feng X, Chuhjo T, Sugimori C, Kotani T, Lu X, Takami A, Takamatsu H, Yamazaki H, Nakao S: Diazepam-binding inhibitor-related protein 1: A candidate autoantigen in acquired aplastic anemia patients harboring a minor population of paroxysmal nocturnal hemoglobinuria-type cells. Blood 2004;104: 2425-2431.

18 Takamatsu H, Feng X, Chuhjo T, Lu X, Sugimori C, Okawa K, Yamamoto M, Iseki S, Nakao S: Specific antibodies to moesin, a membrane-cytoskeleton linker protein, are frequently detected in patients with acquired aplastic anemia. Blood 2007;109:2514-2520.

19 Qi Z, Takamatsu H, Espinoza JL, Lu X, Sugimori N, Yamazaki H, Okawa K, Nakao S: Autoantibodies specific to HNRNP K: A new diagnostic marker for immune pathophysiology in aplastic anemia. Ann Hematol 2010; 89:1255-1263.

20 Takamatsu H, Yagasaki H, Takahashi Y, Hama A, Saikawa Y, Yachie A, Koizumi S, Kojima S, Nakao S: Aplastic anemia successfully treated with rituximab: the possible role of aplastic anemia-associated autoantibodies as a marker for response. Eur J Haematol 2011;86:541-545. 